\title{
TAX REFORM AND THE PROGRESSIVITY OF PERSONAL INCOME TAX IN SOUTH AFRICA
}

MOREKWA E. NYAMONGO AND NICOLAAS J. SCHOEMAN

\begin{abstract}
This paper investigates the progressivity of personal income tax in South Africa over the period 1989 to 2003. We use the effective, redistributive and disproportionality measures of progressivity and find that progressivity of the tax system increased over the period 1990 to 1994. However, during the first phase of the reform programmes the results are inconclusive with the Kakwani index (disproportionality measure) showing increased progressivity. The redistributive effect measure, on the other hand, indicates a marginal decline in progressivity. During the second phase of the reform programmes, both techniques suggest a worsening in progressivity. One explanation for the decline in progressivity during the latter period in the analysis is the fact that many more "new" taxpayers entered the tax net (higher income groups in our database) which made the distribution of pre-tax income more unequal thus impacting on progressivity. On the other hand, the disproportionality measure shows a continuous, albeit volatile increase in progressivity over the latter period under investigation.
\end{abstract}

Keywords: Progressivity, effective progression, redistributive effect, disproporionality

\section{INTRODUCTION}

The progressivity of the tax system has been the subject of discussion in economics since the classics and a voluminous literature exists explaining the importance of progressivity of a tax in order for it to comply with the principle of fairness of a "good tax". The earliest work on measurement of progressivity is associated with Pigou (1929), who suggested that it be measured in terms of average rates of progression. Slitor (1948) acknowledged that no convenient and effective method was available to assist in the measurement and quantitative analysis of tax schedules. He therefore developed a method of measuring the effective rate of progression using the difference between marginal and effective rates, divided by net income before exemptions. Musgrave and Thin (1948) advanced the work of Pigou (1929) and Slitor (1948) by introducing the concept effective progression in order to explain the impact of tax on income distribution. Reynolds and Smolensky (1977), on the other hand, highlighted the redistributive effect, while Kakwani (1977) developed the disproportionality measure of progressivity.

A number of empirical studies for different countries have been conducted in this area. For example, Scott and Triest (1993) analysed the way in which different states in Canada modified the progressivity of their personal income tax (PIT) systems in response to federal tax changes during the 1980s. They observed that decreases in marginal tax rates implemented by the federal government, decreased the value of deductions relevant to state income tax payments, which could cause an increase in effective state progressivity. 
Using PIT returns for the period 1984-1989, they found a decrease in statutory tax progressivity over this period. However, tax payments net of federal subsidies showed a sharp increase in tax progressivity.

In Spain, Lambert and Ramos (1997) studied inequality in pre- and post-tax income distribution and used the redistributive effect measure of progressivity for the period 19851991. They found PIT to be progressive and that the level of progressivity actually increased rapidly during this period.

Caminada and Goudswaard (2001) investigated whether a flat rate individual income tax would reduce tax progressivity in the Netherlands. In this study they constructed a flat rate/broad based individual income tax system and compared the distribution of the existing income in the Netherlands, to the distribution of a simulated flat rate tax. Based on the simulations they found that after drastic base broadening, a proportional rate of $27-7 \%$ would balance the budget and such a flat rate would cause only relatively small changes in average tax ratios. They also found that tax progressivity is mainly affected by fixed personal exemptions as maintained in the simulated flat rate.

In Norway, Thoresen (2004) investigated the phenomenon of reduced tax progressivity in the nineties. His main findings indicate that inequality of pre-tax income increased while the concentration of taxes remained largely unaltered. In order to identify the effect of tax changes on reduced tax progressivity, he used individual income data. Among the OECD countries, Wagstaff and Van Doorslaer (2001) did a comparative analysis among 15 countries to identify the factors that cause PIT to be progressive. Among these countries they found that in Australia, France, Italy, the Netherlands, and Spain, the rate effect is dominant while allowances seem to be prominent in the English-speaking countries other than Australia. They also found some countries like Belgium, Finland, Germany and Sweden, where roughly half of the progressivity of gross tax liability could be attributed to the rate structure or exhibit mixed results.

Achieving progressivity in less developed countries, where the efficiency of the tax system is a great concern, poses a major challenge (Tanzi and Zee, 2001). In these countries income is unevenly distributed, and rich individuals exert influence through their economic and political dominance thus frustrating fiscal reforms. Due to this dominance the revenue base is often not fully exploited and taxes like PIT and property taxes are not fully utilised to achieve progressivity. In these countries, for example, revenue from income tax is limited because of the relatively small number of people subjected to this type of tax, with numbers declining as the income level increases. In order for these countries to maintain nominal progressivity they tend to maintain multiple rate brackets and are reluctant to adopt reforms that would reduce the number of brackets. The situation is worsened by the high level of personal exemptions that accrue as income rises.

Policy makers have a range of instruments that could be used to increase progressivity. According to Wagstaff and Van Doorslaer (2001), the most important ones include the rate structures and allowances for single and married persons, as well as deductions such as mortgage interest payments and private health insurance contributions. Tax credits on the other hand, reduce net tax liability while the exemption of certain types of income also affects progressivity.

The rest of the paper is structured as follows: section 2 contains an overview of income tax reforms since 1994. Section 3 explains various methods to measure progressivity with the model results on the progressivity of PIT in South Africa in section 4. The paper concludes with section 5 . 


\section{A REVIEW OF MAJOR INCOME TAX DEVELOPMENTS IN SOUTH AFRICA}

\subsection{Income Tax Reforms between 1989 and 2004}

A number of income tax reforms were introduced during this period. For example, in 1989, the income tax codes allowed for differentiation between married and unmarried persons. The schedule for married persons consisted of 19 tax brackets with the lowest marginal tax rate at $14 \%$, applicable to income levels less than $\mathrm{R} 14,000$. The highest marginal tax rate was $45 \%$ and applicable to income levels exceeding $\mathrm{R} 80,000$. The schedule for unmarried persons also contained 19 tax brackets with the highest marginal rate of $45 \%$ and thresholds of R 10,000 at the lower level and R 54,000 at the top marginal level. Thus, the income tax codes at that time discriminated against unmarried persons.

In 1990, an additional schedule was introduced for married women consisting of seven tax brackets with the lowest marginal tax rate at $20 \%$ and the threshold at R 20,000. The top marginal rate was adjusted to $38 \%$ and applied to income exceeding R 40,000. In 1991, the number of income brackets were reduced from 19 to 15 for married and 14 for unmarried persons while that of married women increased to 11 brackets. A further reduction in the number of brackets occurred in 1993, when the number of income brackets for married persons were reduced to 11 and for unmarried persons to nine, while those for married women were reduced to only eight brackets.

After the orderly transition in 1994, the new government embarked on reforms that affected virtually all aspects of the economy and the tax laws were no exception. The Katz Commission was appointed with the brief to inquire into the appropriateness and efficiency of the tax system and to make recommendations taking into account internationally accepted tax principles and practices. The Commission made a number of recommendations of which some were implemented in two phases.

The first phase of reforms covered the period from 1994 to 1999, and was characterised by policy reviews, investigations and reports produced by the Katz Commission, which occasioned numerous tax amendments that were promulgated during that period. With regard to income tax, the Commission investigated the status of the system with the emphasis on gender issues, tax base, tax thresholds, income brackets, tax rates, progressivity fiscal drag and income tax exemptions for charitable, religious and educational institutions.

During the period 1994 to 1995, the number of taxable income brackets were reduced to 10 for married men and nine for unmarried persons while those for married women were reduced to eight. In 1996, the tax law harmonised the various tax schedules into two different groups, namely a schedule for natural persons (PIT) including all individuals married or unmarried and a schedule for unnatural persons (businesses). The tax brackets applying to natural persons were set at 10 while those for unnatural persons were set at 11 . This measure managed to eliminate the discriminatory provisions in the income tax laws. However, during the 1997/1998 financial year, the tax schedules were consolidated into one structure with only six brackets, with the highest marginal rate set at $45 \%$ on the taxable income bracket $\mathrm{R}$ 100,000 and above.

Other major reforms during the first phase included the introduction of transfer pricing and capitalisation rules in 1995- Furthermore, income tax legislation changes included the repealing of the general anti-avoidance provision in 1996 which was meant to reduce the tax gap and increase tax collections. Anti-avoidance provisions with regard 
to fringe benefits were introduced in 1997 and 1999 to check the abuse of travel allowances, company car schemes and residential accommodation for employees. A tax amnesty was announced in 1995 aimed at persons not registered as taxpayers with the intention to increase the number of taxpayers and hence revenue collection.

The second phase of reform, started from 2000 onwards, focussing on the broadening of the tax base and adapting the tax system to conform to international tax law. The most fundamental change in income tax policy was the change from a "source-based" to a "residence-based", system in 2001. This was intended to protect and broaden the tax base and provide the South African income tax system with a flavour that conforms to international standards and practices. Other changes introduced during the second phase included the introduction of the concept "public benefit organisation". Child rebates were abolished in order to minimise fraudulent claims. To compensate for inflation, the tax brackets and tax thresholds were adjusted annually. A second amnesty was announced in 2003, aimed at assisting taxpayers who had transgressed the South African exchange control regulations by transferring funds offshore without proper authorisation.

All these reforms were meant not only to enhance revenue collection, but also to ensure that the PIT system is not discriminatory and conforms to international standards.

\subsection{Structure and Trends of Tax Revenue in South Africa}

Fig. 1 shows the relative contribution of the various types of taxes to total tax revenue during the period 1990-2004. From the figure it is apparent that PIT accounted for the highest share of tax revenue in South Africa (37\%). This was $11 \%$ higher than value added tax (VAT) which, at 26\%, accounted for the second highest share. Corporate income tax (CIT) on the other hand, contributed only $19 \%$ of total tax revenue. The balance (18\%) consisted of "other taxes", for example, international taxes.

Fig. 2 shows some structural changes in the shares of different types of taxes over the period under investigation. From the figure it is evident that PIT accounted for the highest share of total tax revenue during the entire 1990-2004 period. During the early 1990s it followed an upward trend, growing by an average of $12.7 \%$ between 1990 and 1993However, it declined marginally by $1.6 \%$ between 1994 and 1995, before increasing modestly by $1.4 \%$ between 1996 and 1999- Thereafter, it declined reaching a low of 33-1\% in 2004. Over the entire period the share of PIT grew by $0.4 \%$, which suggests that the share of PIT has remained relatively stable. On the other hand, VAT shows an upward trend during this period with an average increase of $1.2 \%$. International

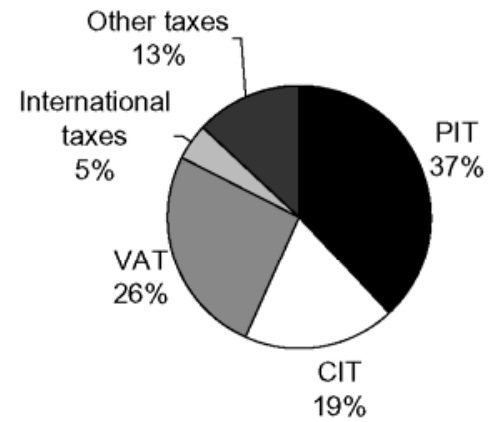

Figure 1. Averages for the composition of tax revenue in South Africa: 1990-2004 Source: South African Reserve Bank: Quarterly Bulletin, various issues. 


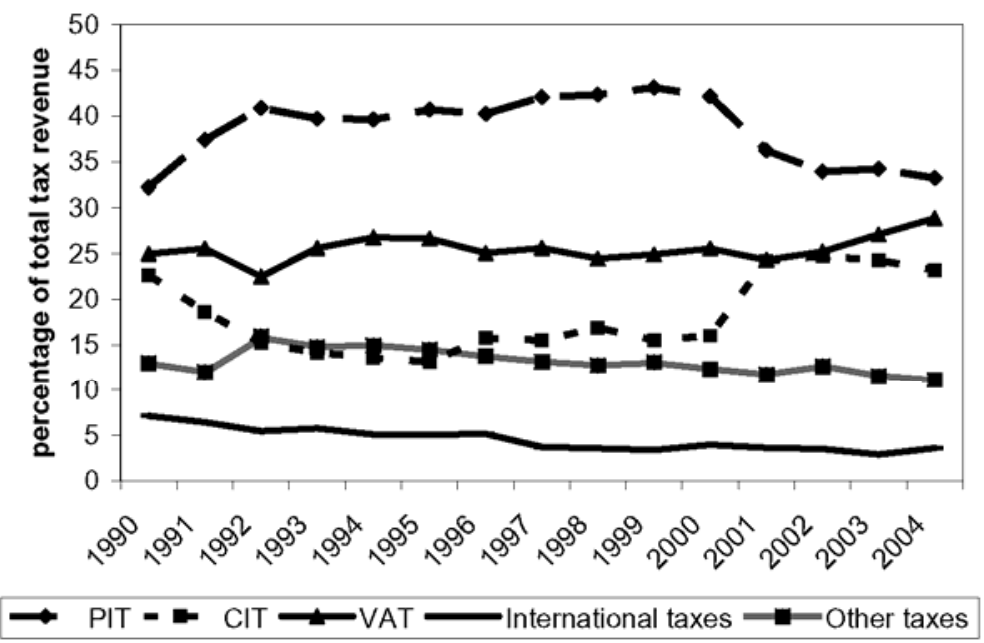

Figure 2. Trend in revenue collection from different sources in South Africa: 1990-2004 Source: South African Reserve Bank: Quarterly Bulletin, various issues.

taxes and "other taxes" showed a declining trend which averaged $-3-9 \%$ and $-0.6 \%$, respectively.

In view of the observed trends of the various revenue components it is important to single out PIT and VAT for further analysis as they affect the level and distribution of incomes of individuals. Fig. 2 shows that the trends of PIT and VAT can be classified into three distinct phases. The first phase covers the period 1990 to 1992, when the share of PIT in total revenue was rising and the share of VAT declining. This has important implications on the distribution of personal incomes. The fact that the share of PIT in total revenue was rising, implies that the government was relying more on PIT to redistribute income and raise revenue. On the other hand, the share of VAT in total revenue was declining and because VAT is regressive in nature it implies that reducing its share may have contributed towards improving the individual income distribution during this period. The second phase covers the period 1993-1999, when the relative shares of PIT and VAT remained rather stable. This may suggest that during this period the tax policy did not contribute much to changing the existing distribution of personal income. During the third phase from 2000 to 2004, the relative shares of PIT and VAT were affected. While the relative share of PIT was declining, that of VAT was rising. This suggests that the tax policy at this time may have contributed towards a redistribution of income from the lower to higher income groups. Due to the regressive nature of VAT, this tendency could mean that income distribution became more unequal.

\section{MEASUREMENT OF TAX PROGRESSIVITY}

A number of methods in the literature are suggested that seek to measure tax progressivity In this section we discuss some of them.

The Pigouvian Approach: Progression can be measured in two ways, namely the average tax progression measure and the marginal tax rate progression measure (Pigou, 1929). 
The average tax progression measure is founded on the premise that the tax structure is progressive when the average tax rate increases with rising income. In other words, progression is the rate of change of the average tax rate. Formally stated, suppose the initial income is $Y_{0}$ and the tax rate at this level of income is $T_{0}$, when income rises to $Y_{1}$ and the tax rate increases to $T_{1}$, the average rate progression $\left(\mathrm{P}_{\mathrm{a}}\right)$ is given as;

$P_{a}=\frac{T_{1} / Y_{1}-T_{0} / Y_{0}}{Y_{1}-Y_{0}}$

Based on this formula, a tax is proportional if $\mathrm{P}_{\mathrm{a}}$ is equal to zero, progressive if it is positive and negative when it is regressive.

Marginal rate progression, on the other hand, focuses on the rate of change in the marginal tax rate and is calculated as follows:

$P_{m}=\frac{\frac{T_{2}-T_{1}}{Y_{2}-Y_{1}}-\frac{T_{1}-T_{0}}{Y_{1}-Y_{0}}}{Y_{2}-Y_{1}} \quad \mathrm{Y}_{2}>\mathrm{Y}_{1}>\mathrm{Y}_{0}$ and $\quad \mathrm{T}_{2}>\mathrm{T}_{1}>\mathrm{T}_{0}$

Using this criteria, a tax structure is proportional if the coefficient $\mathrm{P}_{m}$ is equal to zero, progressive if the coefficient is positive and regressive if the coefficient is negative.

The Slitor Index Approach: This index (Slitor, 1948) measures progressivity as follows: a tax system is progressive, proportional or regressive if the marginal tax rate is greater, equal or less than the average tax rate, respectively. According to this method progressivity is measured as follows: ${ }^{1}$

$\frac{d t(Y)}{d Y}=\frac{m(Y)-t(Y)}{Y}$

where $t(\mathrm{Y})$ is the average tax rate at income level $\mathrm{Y}$ and $\mathrm{m}(\mathrm{Y})$ is the marginal tax rate at the same level of income.

The Musgrave and Thin Approach: Musgrave and Thin (1948) developed measures that sought to address the limitations of the approach developed by the Pigouvian and Slitor indices. They suggested that progressivity be measured using the Liability Progression Index, Residual Income Progression Index and Effective Progression Index. The Liability Progression Index is based on changes in tax liability and is defined as the ratio of the percentage change in tax liability to the concurrent percentage change in income. This is formally stated as:

$P_{L}=\frac{T_{1}-T_{0}}{T_{0}} \frac{Y_{0}}{Y_{1}-Y_{0}}$

\footnotetext{
${ }^{1}$ Assuming the tax liability $\mathrm{T}$ is expressed as a proportion of income as $T=f(Y)$, the average rate for tax is therefore expressed as $f\{Y) I Y$. If this function is differentiated with respect to $\mathrm{Y}$, we obtain $\frac{1}{Y^{2}}\left[Y f^{\prime}(Y)-f(Y)\right]=\frac{1}{Y}\left[f^{\prime}(y)-\frac{f(Y)}{Y}\right]$.
} 


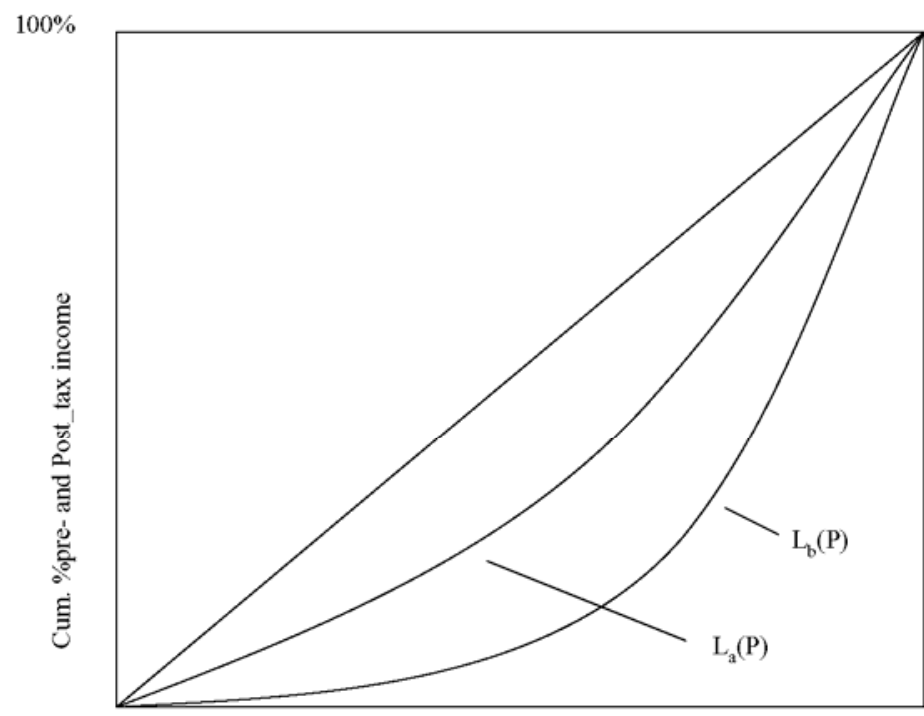

Cum. \% taxpayers

$100 \%$

Figure 3. Lorenz curves for pre-tax and post-tax income

In this case the liability progression coefficient will take on a value of 1 where the tax is proportional, exceed 1 where the tax is progressive and be less than 1 when the tax is regressive.

The Residual income progression index, on the other hand, defines progression as the ratio of the percentage change in income after tax to the percentage change in income before tax, that is,

$$
P_{R}=\frac{\left(Y_{1}-T_{0}\right)-\left(Y_{0}-T_{0}\right)}{Y_{0}-T_{0}} \frac{Y_{0}}{Y_{1}-Y_{0}}
$$

A tax is considered to be proportional when it has a value of 1 , exceeds 1 when it is regressive and is less than 1 when it is progressive.

The methods discussed above, however, suffer from a serious limitation, namely they are only capable of measuring progression at a given point on the taxable income scale. They do not therefore provide a unique index to determine whether or not the tax system, generally, exhibits progressivity regressivity or proportionality This limitation is addressed by the methods discussed below.

Effective Progression Index: This index measures progression in terms of the rate structure and in terms of income distribution. In this regard, effective progression measures the extent to which a given tax structure results in a shift in the distribution of income towards equality. It uses Lorenz curves (see Lorenz, 1905) to visualise progression and Gini coefficients (see Glasser, 1962; Brown, 1994; Cowel, 2000; Jean_Yves, 2000) to measure the extent to which a change in the tax rate can affect income distribution as shown in Fig. 3- In this regard Gini coefficients for pre-tax and post-tax are calculated and the effective progression, $\pi_{e f}$ is stated as: 
$\pi_{f f}=\frac{G_{b}}{G_{a}}=\frac{\int_{0}^{1} L_{b}(P) d P}{\int_{0}^{1} L_{a}(P) d P}$

where $\pi_{e f}$ is the effective progression index, $\mathrm{G}_{\mathrm{a}}$ is the Gini coefficient of equality of post-tax income and $G_{b}$ is the Gini coefficient of pre-tax income. $L_{a}(P)$ is the Lorenz curve

of post-tax income and $L_{b}(P)$ is the Lorenz curve of pre-tax income which are shown in

Fig. 3 - If the tax structure is proportional the coefficient will be 1 , exceeds 1 where the tax is progressive and is less than 1 where it is regressive.

Redistributive Effect Approach: Reynolds and Smolensky (1977) suggested a modification to the Musgrave and Thin (1948) method, stating that the redistribution effect of a tax be measured as the difference between the distribution of pre-tax income and income post-tax income, which is formally stated as:

$\pi_{M}=2 \int_{0}^{1}\left[L_{b}(P)-L_{a}(P)\right] d P=G_{b}-G_{a}$

If the index $\pi_{M}$ is negative, it means that income is distributed more unequally after the tax and therefore the tax is regressive. On the other hand, if this expression is positive then the tax system is progressive; however, if this expression is zero in which case a tax does not cause any effect on the distribution of incomes, then the tax is said to be proportional. Fig. 3 above serves to illustrate this measure of progressivity using Lorenz curves.

In the Fig., $L_{a}(P)$ is the Lorenz curve of post-tax income while, $L_{b}(P)$ is the Lorenz curve for pre-tax income. On this basis, it is argued that if the tax is progressive, $L_{a}(P)$ curve will lie above the $L_{b}(P)$ curve, this is because a progressive tax is associated with a decrease in income inequality. However, where the tax is regressive, the $\mathrm{L}_{b}(\mathrm{P})$ curve will lie above the $L_{a}(P)$ curve, as regressive taxes are associated with high income inequality and it is proportional if the two curves coincide. The redistributive effect of progressivity is double the area between the two Lorenz curves.

Disproportionality Approach: This approach was developed by Kakwani (1977) and not only considers the distribution of pre-tax and post-tax income as suggested by Musgrave and Thin (1948), but also the level of concentration of the PIT. Kakwani (1977) argues that simply comparing the pre-tax and post-tax income distribution may not yield a suitable measure of progressivity. He suggests instead, that the Lorenz curve of income be compared to the concentration curve ${ }^{2}$ of PIT.

Fig. 4 shows the Lorenz curve for pre-tax income distribution and the personal income tax concentration curve. To measure progressivity, Kakwani (1977) developed an index in which progressivity is defined in terms of the departure from proportionality which is defined formally as:

${ }^{2}$ A concentration curve of a tax is defined as a curve that plots the cumulative taxes and cumulative number of individuals paying the tax. 


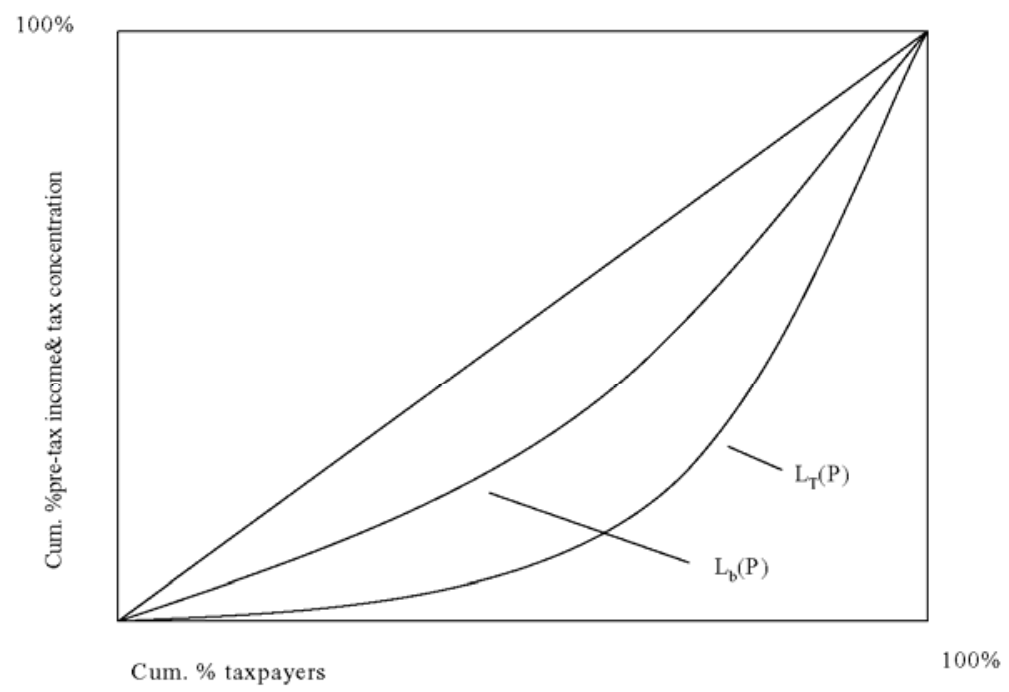

Figure 4. Lorenz curve and tax concentration curve

$\pi_{K}=2 \int_{0}^{1}\left[L_{b}(P)-L_{T}(P)\right] d P=C_{T}-G_{b}$

where, $\mathrm{L}_{b}(\mathrm{P})$ is the Lorenz curve of pre-tax income, $\mathrm{L}_{T}(\mathrm{P})$ is the concentration curve for net tax liabilities, $C_{T}$ is the concentration index for net tax liabilities and $G_{b}$ is the Gini coefficient for pre-tax income. According to this method, if the tax system is progressive, that is payments expressed as a fraction of income rise with income, $L_{T}(P)$ will lie below $\mathrm{L}_{b}(\mathrm{P})$. Similarly, if a tax system is regressive $\mathrm{L}_{T}(\mathrm{P})$ lies above $\mathrm{L}_{b}(\mathrm{P})$. It is only when the tax is proportional that the two curves coincide. As pointed out by Wagstaff and Van Doorslaer (2001), the index developed by Kakwani, $\pi_{K}$ is defined as double the area between $\mathrm{L}_{b}(\mathrm{P})$ and $\mathrm{L}_{\mathrm{T}}(\mathrm{P})$.

\section{EMPIRICAL RESULTS OF PROGRESSIVITY IN SOUTH AFRICA}

The empirical results reported in this section are based on the procedures developed by Musgrave and Thin (1948), Reynolds and Smolensky (1977) and Kakwani (1977)- ${ }^{3}$ Data for this study was obtained from the database maintained at the Bureau for Economic Policy and Analysis at the University of Pretoria.

\subsection{PIT Progressivity Based on the Musgrave and Thin Approach}

The graphical representation of progressivity as suggested above is done by constructing the relevant Lorenz curves, which are shown in Appendix 1. The figures in Appendix 1 show that the Lorenz curves for post-tax income distribution are above the Lorenz curves of pretax income. This, therefore, shows that during the period under review,

\footnotetext{
${ }^{3}$ To conserve space the results from other measures of progressivity that are discussed in this article are not reported, they are available on request from the authors, however.
} 
Table 1. Effective and redistributive effect measures of progressivity

\begin{tabular}{llllll}
\hline & $\mathbf{1 9 8 9}$ & $\mathbf{1 9 9 0}$ & $\mathbf{1 9 9 4}$ & $\mathbf{1 9 9 9 / 0 0}$ & $\mathbf{2 0 0 3 / 0 4}$ \\
Pre-tax income inequality, $\mathrm{G}_{\mathrm{b}}$ & 0.584 & 0.523 & 0.504 & 0.626 & 0.592 \\
Post-tax income inequality, $\mathrm{G}_{\mathrm{a}}$ & 0.535 & 0.489 & 0.454 & 0.578 & 0.575 \\
Effective progression index, $\pi_{f}=G_{b} / G_{a}$ & 1.092 & 1.070 & 1.110 & 1.083 & 1.030 \\
Redistributive effect index, $\pi_{M}=G_{b}-G_{a}$ & 0.049 & 0.034 & 0.050 & 0.048 & 0.017 \\
\hline
\end{tabular}

the PIT structure exhibits progressivity. The effect of PIT on income distribution is double the area between the pre-tax and post-tax Lorenz curves. However, in order to know whether progressivity has changed over this period and also to establish the distributional effects of the various personal income s, the respective Gini coefficients for each of the data points included in this study are calculated and presented in Table 1.

Table 1 shows the indices of progressivity realised for selected years. It is evident that the pre-tax income distribution became more equal by 3-6\% while post-tax became more equal by $7-2 \%$ when comparing 1990 and 1994. However, the effect of PIT is evident as the posttax income distribution became more equal during this period. From Figs. 1 and 2 is deduced that PIT is the largest source of tax revenue in South Africa which implies that it was critical in improving income distribution during this time. When one compares the period 1999/2000 to $2003 / 2004$, pre-tax income distribution became more equal by $5-4 \%$. Further analysis shows a marginal change in pre-tax income distribution by $1.4 \%$ when comparing 1989 to 2003/2004, while post tax income distribution became more unequal by $7-5 \%$. This finding suggests that other policies were initiated by the government to improve the distribution of pre-tax income.

In terms of effective progression of the PIT, it is clear that the system displays characteristics of a progressive system over the period 1989 to 2003/2004. However, it is noted that the income tax system did not display increased progressivity over the entire period. When comparing 1989 to 1990, the degree of progressivity declined by $2.0 \%$, while comparing 1990 to 1994 shows progressivity improved by 3-4\%. This suggests that during the period 1989 to 1994, PIT progressivity improved by 1.5\%. A decrease in effective progressivity of $2.1 \%$ was realised when comparing 1994 to $1999 / 2000$, and a further 5-5\% when comparing 1999/2000 to 2003/2004. Overall, effective progressivity of PIT in South Africa declined by $6.1 \%$ when comparing 1989 to 2003/2004. Fig. 5 shows the trend of the effective progression index of PIT in South Africa.

In terms of the redistributive effect of the tax burden, it is noted that when comparing 1990 to 1994 the redistributive effect index grew by 47-1 \% which may suggest that PIT during this period had been characterised by higher levels of progressivity with more equity in income. The first phase of tax reforms that took place during the period 1994-1999/2000 was featured by a decline in redistribution of 4.0\% when comparing 1994 to 1999/2000 and a further $64.6 \%$ during the second phase of reforms between 1999/2000-2003/2004. Overall, there was a decline in redistribution of 65-3\% when comparing 1989 and 2003/2004. In view of the above, it is clear that the tax system in South Africa was more progressive before 1994. Figure 6 above shows the trend of the redistributive effect of income tax in South Africa for selected years during the period 1989-2003/2004. 


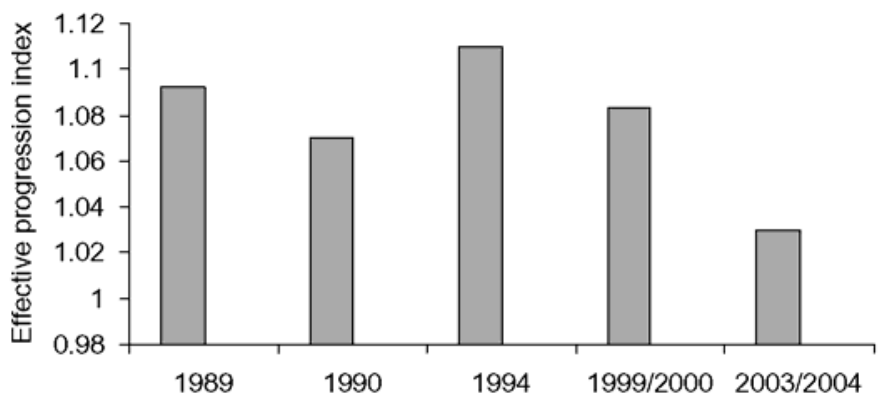

Figure 5. Trend in effective progression of personal income tax

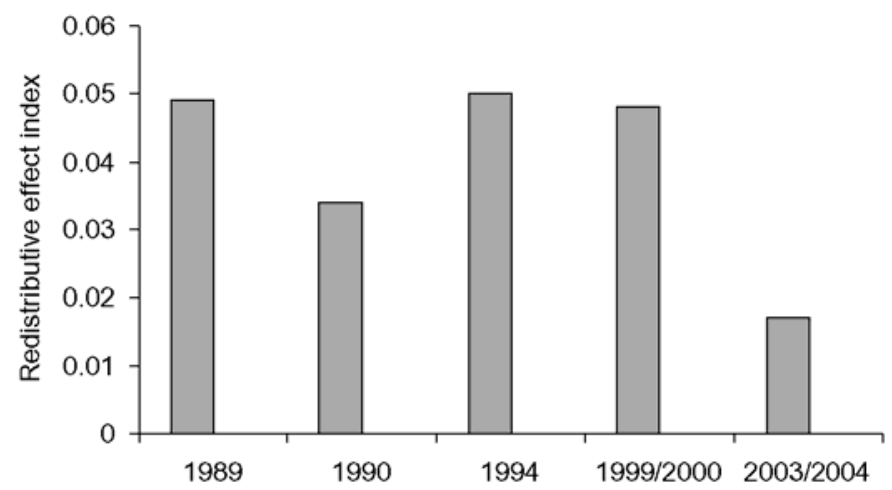

Figure 6. Trend in the redistributive effect index of personal income tax

Table 2. Progressivity measured by disproportionality

\begin{tabular}{llllll}
\hline & $\mathbf{1 9 8 9}$ & $\mathbf{1 9 9 0}$ & $\mathbf{1 9 9 4}$ & $\mathbf{1 9 9 9 / 2 0 0 0}$ & $\mathbf{2 0 0 3 / 2 0 0 4}$ \\
Pre-tax income inequality, $\mathrm{G}_{\mathrm{b}}$ & 0.584 & 0.523 & 0.504 & 0.626 & 0.592 \\
Tax burden concentration, $\mathrm{C}_{\mathrm{T}}$ & 0.662 & 0.575 & 0.595 & 0.771 & 0.724 \\
Disproportionality index, $\boldsymbol{\pi}_{K}=G_{T}-G_{b}$ & 0.078 & 0.052 & 0.091 & 0.145 & 0.132 \\
\hline
\end{tabular}

\subsection{Income Tax Progressivity Based on the Kakwani Procedure}

Using the Kakwani procedure, the graphical representations in Appendix 2 show that PIT in South Africa is progressive since in all cases the tax concentration curve lies below the Lorenz curve. However, although the graph illustrates the progressiveness of the PIT structure in South Africa, it does not show the extent to which the progressivity of PIT has changed over this period. To address this question we construct the relevant Gini coefficients as suggested by Kakwani (1977), and the results are presented in Table 2.

As noted earlier, the inequality of pre-tax income decreased by $6.0 \%$ when comparing 1989 to 2003/2004. It is also evident from the table that the tax concentration declined by 13$1 \%$ when comparing 1989 to 1990, however, it increased by 3-5\% when comparing 1990 to 1994. Comparing 1989 with 1994, tax concentration declined by 


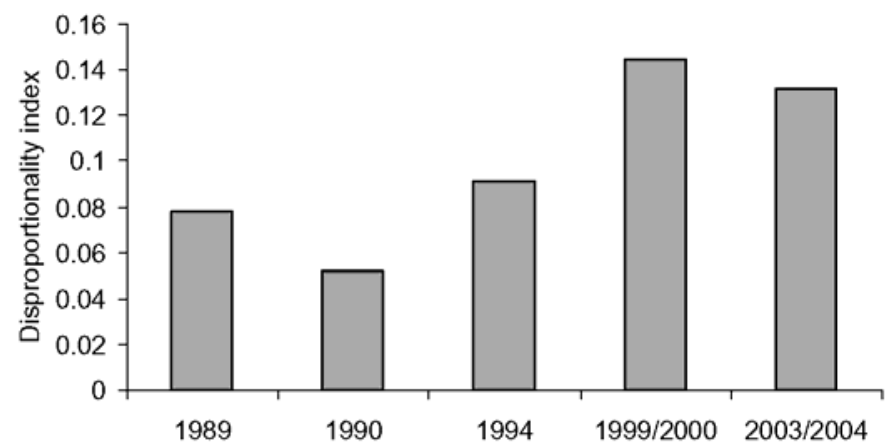

Figure 7. Disproportionality measure of personal income tax progressivity

$10.1 \%$, but increased by $29-6 \%$ and $0.3 \%$, respectively, when 1994 is compared with $1999 / 2000$ and 2003/2004. This suggests that comparing the periods 1994 with 2003/2004, tax concentration changed only marginally. Overall, tax concentration declined by $16.8 \%$ between 1989 and 2003/2004.

However, the Kakwani index (disproportionality measure) shows that PIT largely remained progressive and that the degree of progressivity varied over time. Comparing 1989 to 1994 , progressivity increased by $16.7 \%$. During the first phase of reforms (19941999/2000) progressivity increased by $59.6 \%$ followed by a decline of $9.0 \%$ during the second phase of reforms (1999/2000-2003/2004). Figure 7 shows the trend of tax progressivity in South Africa for selected years between 1989-2003/2004.

\section{CONCLUSION AND RECOMMENDATIONS}

This paper analyses the progressivity of PIT in South Africa during the calender and fiscal years (pending on the availability of data) 1989, 1990, 1994, 1999/2000 and 2003/2004 using the various techniques as described. The results indicate that PIT in South Africa was progressive over the period 1989 to 2003/2004 albeit at a volatile rate. Using the effective progression and redistributive effect methods, it seems, however, that the level of progressivity actually worsened during the period under investigation. On the other hand, using the disproportionality technique, the results show an increase in the level of progressivity.

When the results are decomposed into the pre and post reform phases, the Musgrave and Thin and Kakwani procedures indicate that during the period 1989 to 1990, the progressivity of income taxes declined. However, when comparing 1990 to 1994, both procedures suggest increased progressivity. The first phase of the reform after 1994 produced mixed results. While the Kakwani index (disproportionality measure) shows that progressivity increased impressively, the redistributive effect measure, on the other hand, indicates a marginal decline in progressivity. During the second phase of the reform, both techniques suggest a worsening in progressivity. One possible explanation for the decline in progressivity during the latter period is the fact that many more "new" taxpayers entered "filer" status (higher income groups) which made the pre-tax income distribution more unequal and also impacted on progressivity. 


\section{APPENDICES}

\section{APPENDIX 1}

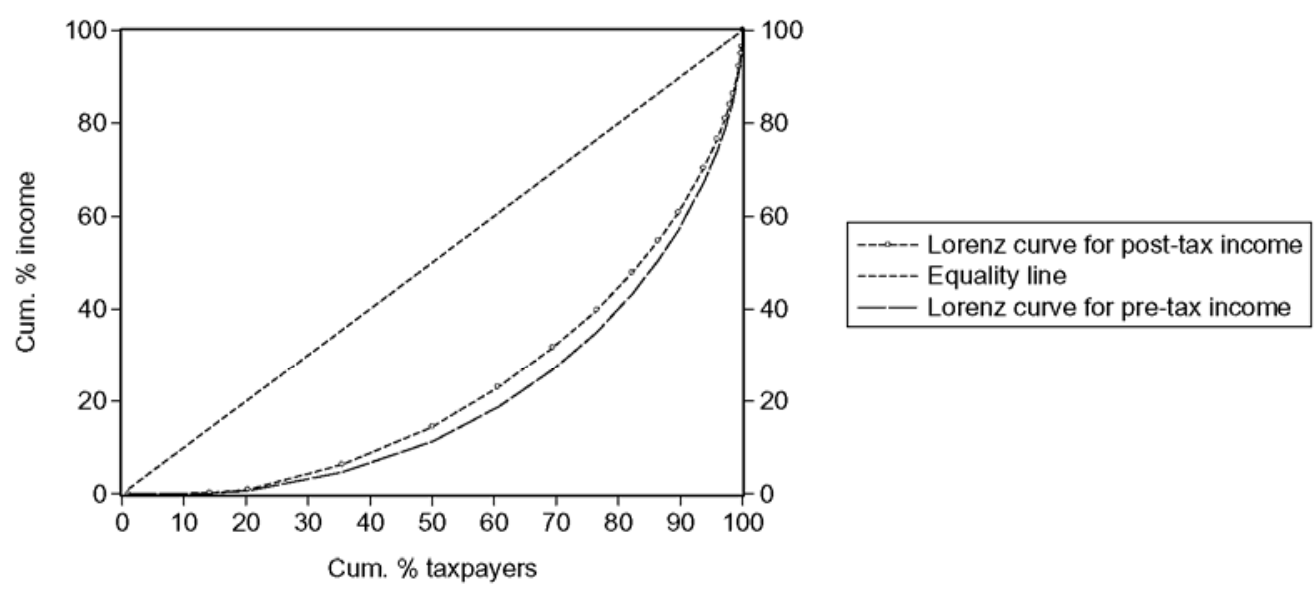

Figure 1A. Lorenz curves for pre-tax and post-tax income: 1989
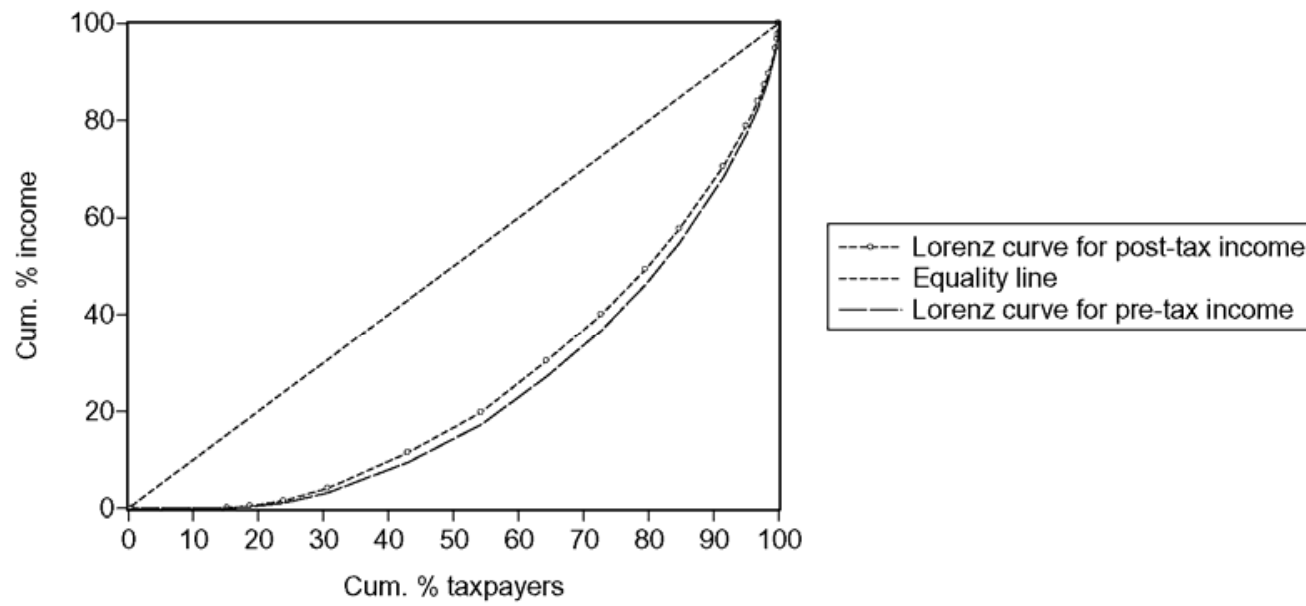

Figure 1B. Lorenz curves for pre-tax and post-tax income: 1990 


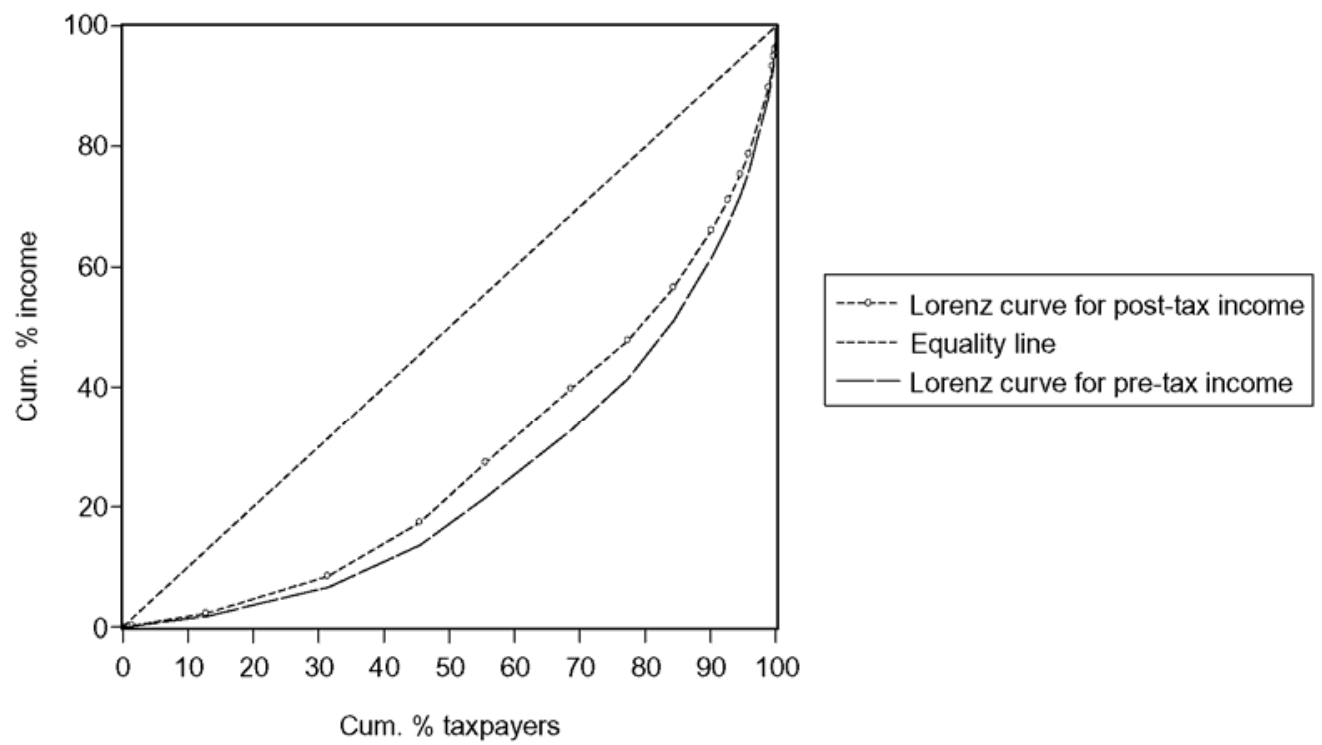

Figure 1C. Lorenz curves for pre-tax and post-tax income: 1994

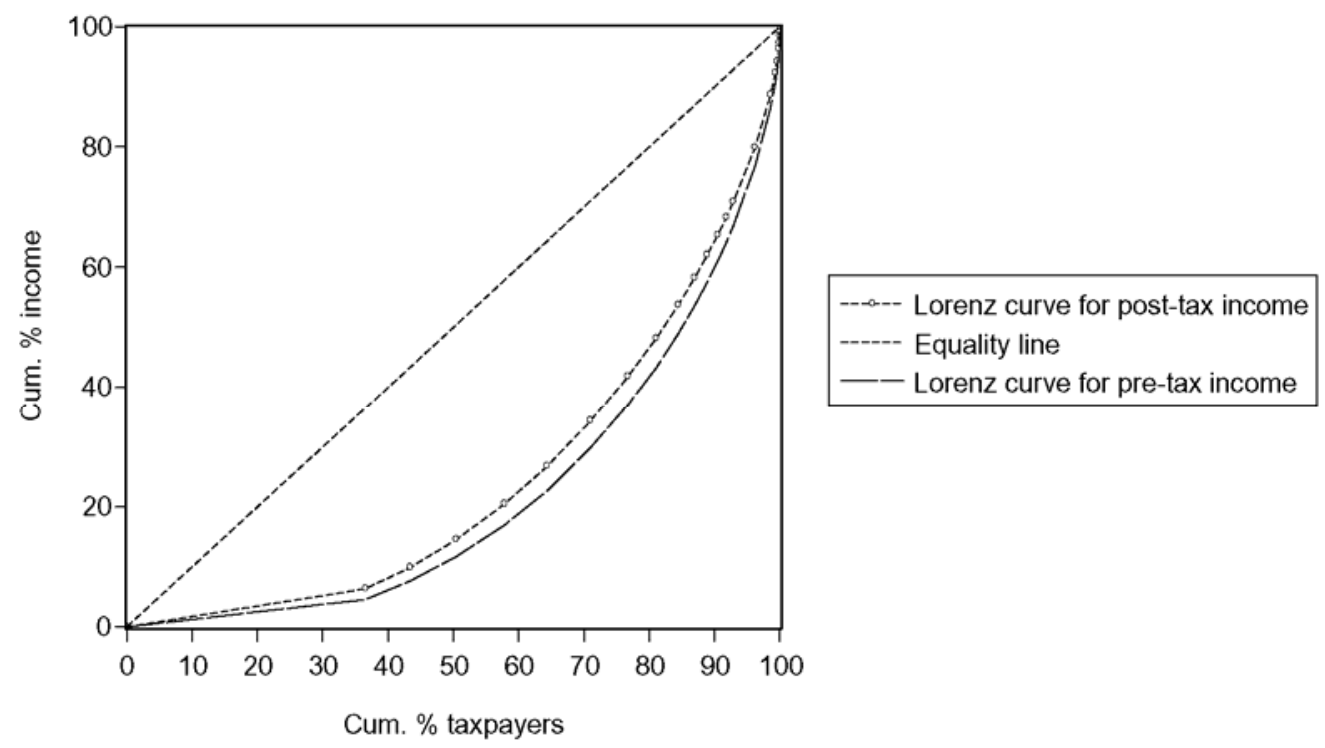

Figure 1D. Lorenz curves for pre-tax and post-tax income: 1999/2000 


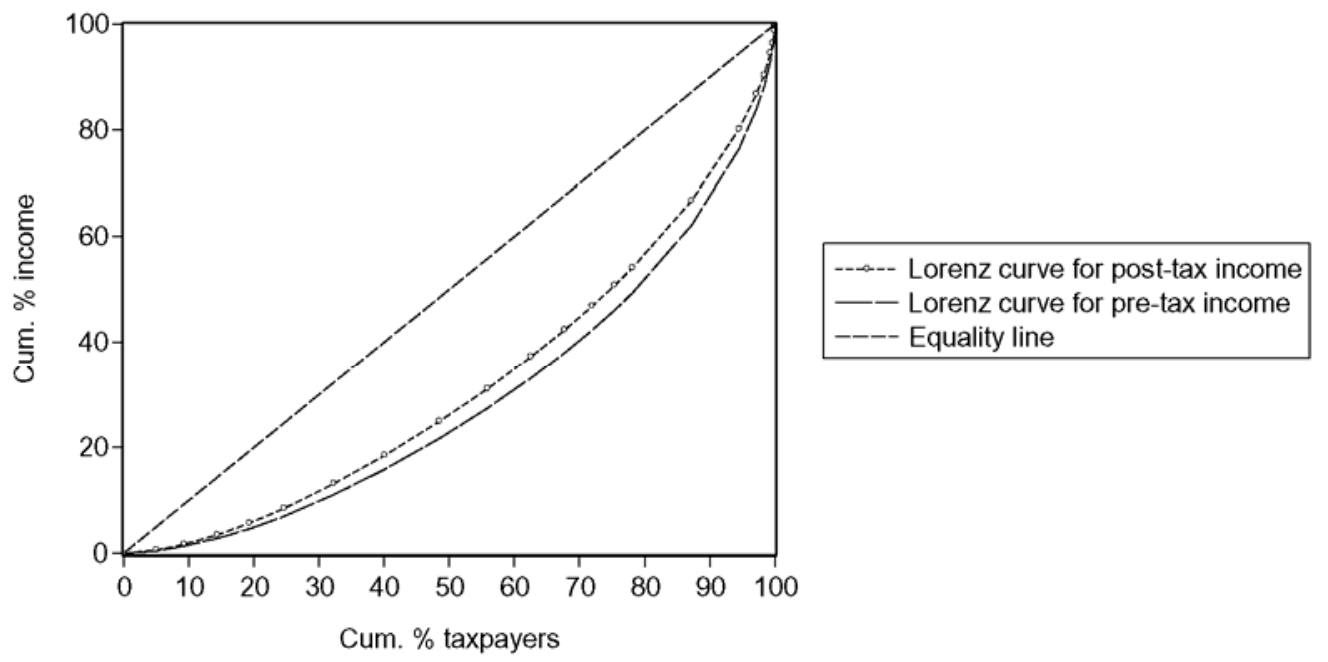

Figure 1E. Lorenz curves for pre-tax and post-tax income: 2003/2004

\section{APPENDIX 2}

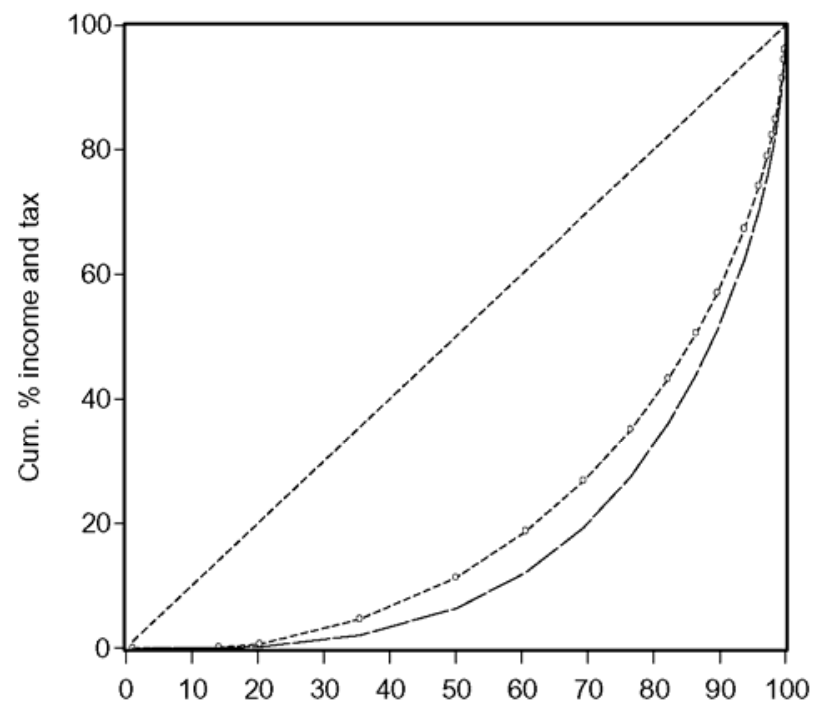

---- Lorenz curve for pre-tax income

------ Equality line

- - Tax concentration curve

Cum. \% taxpayers

Figure 2A. Lorenz curve for pre-tax income and tax concentration: 1989 


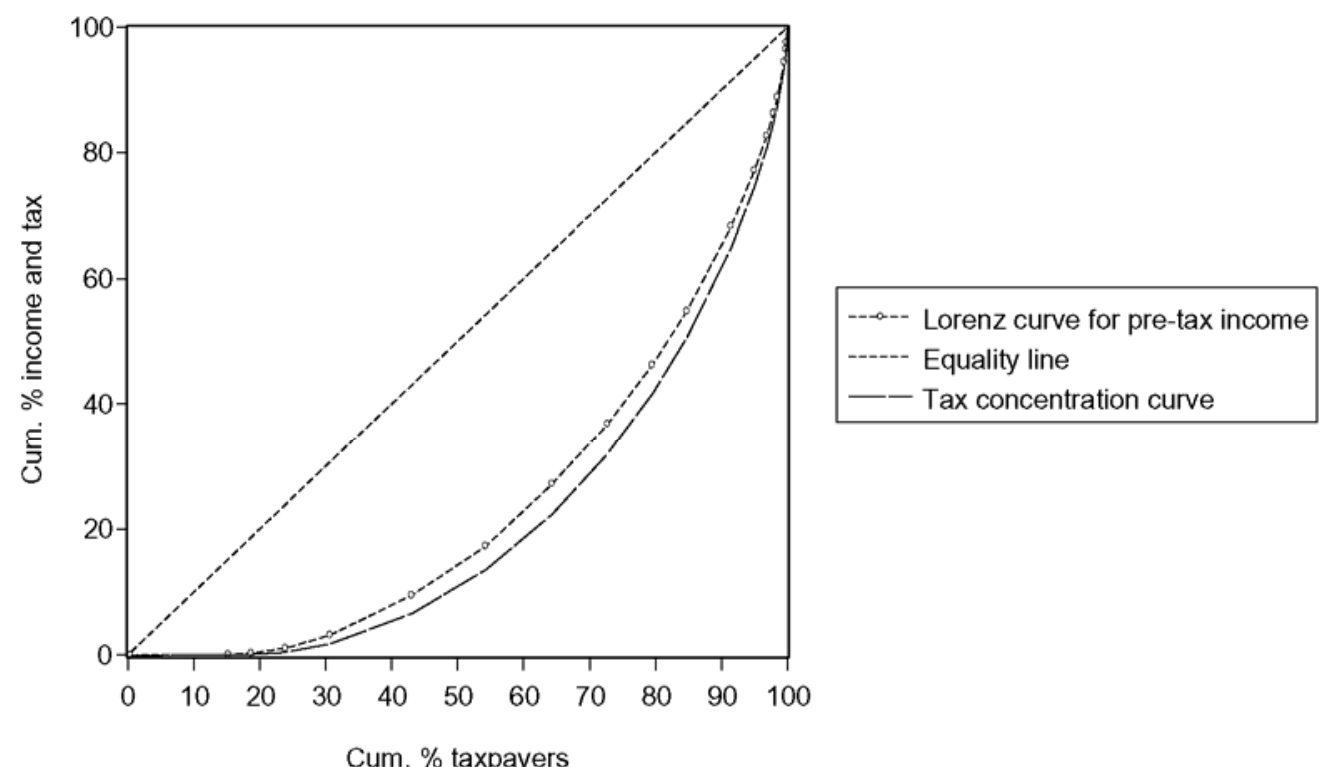

Figure 2B. Lorenz curve for pre-tax income and tax concentration: 1990

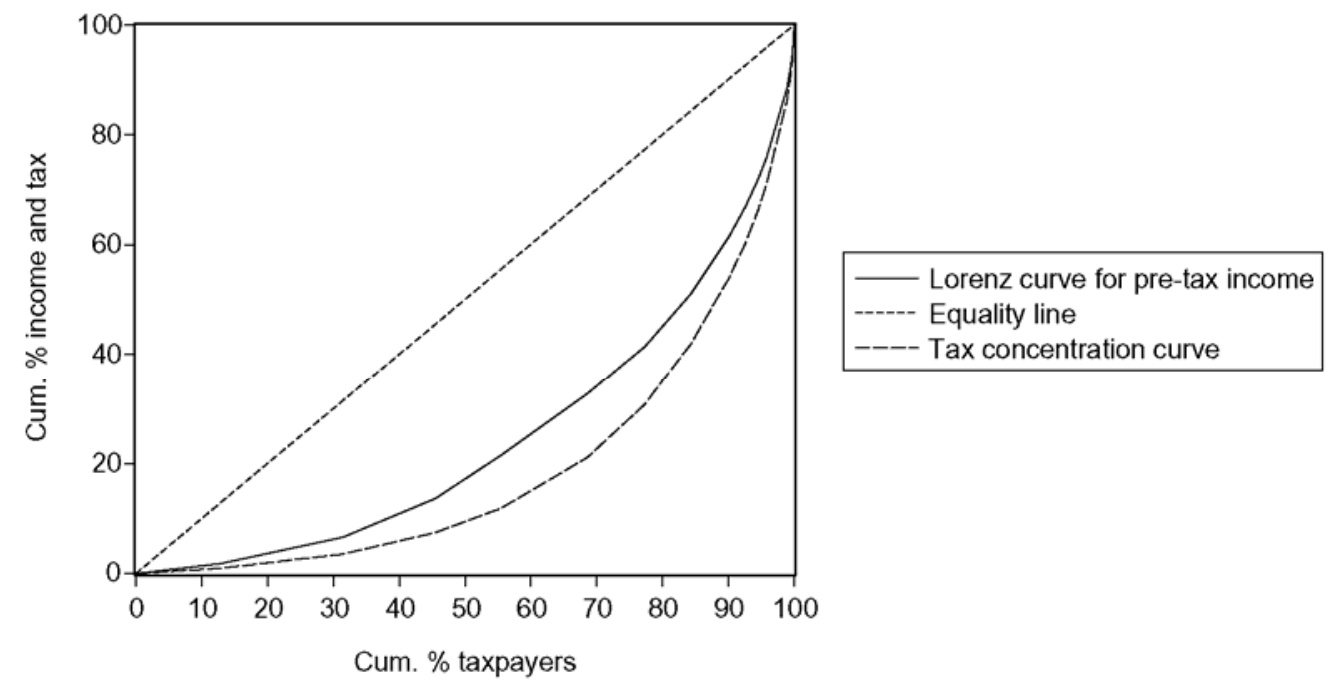

Figure 2C. Lorenz curve for pre-tax income and tax concentration: 1994 


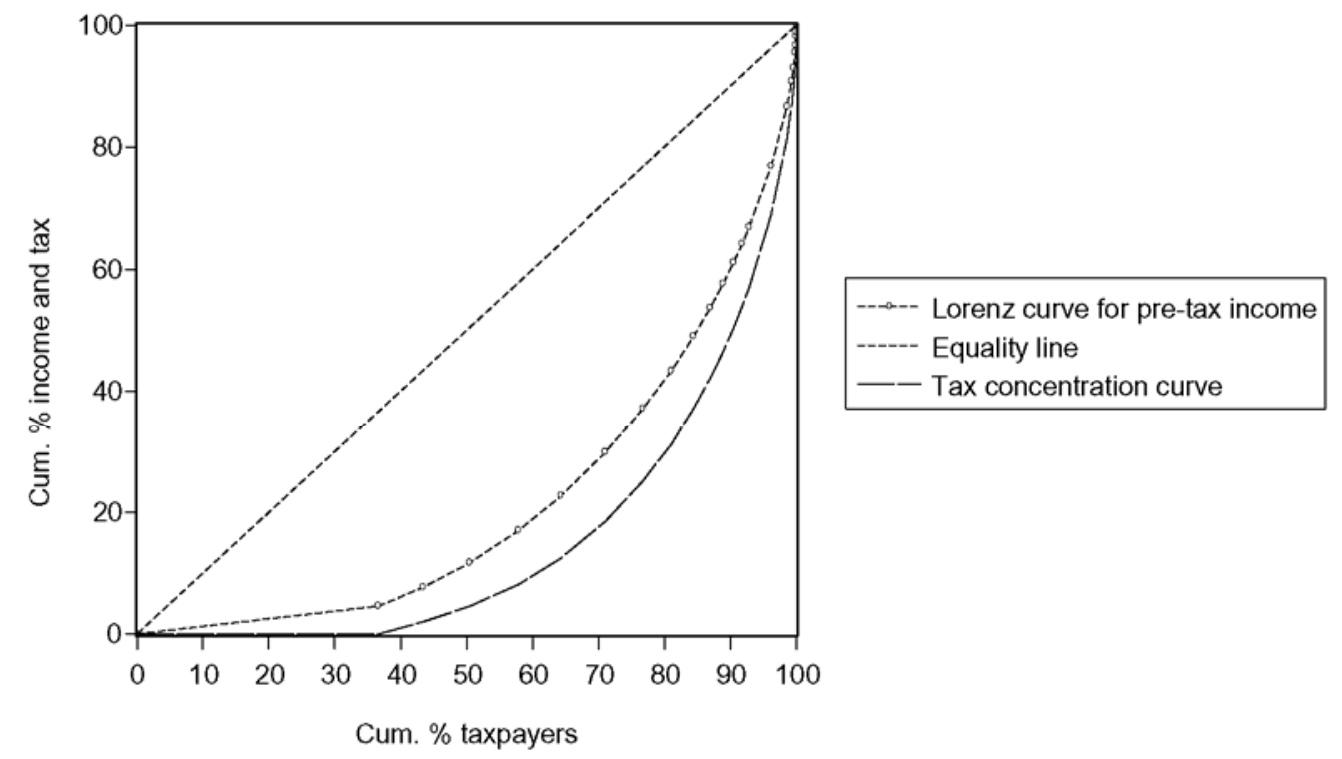

Figure 2D. Lorenz curve for pre-tax income and tax concentration: 1999/2000

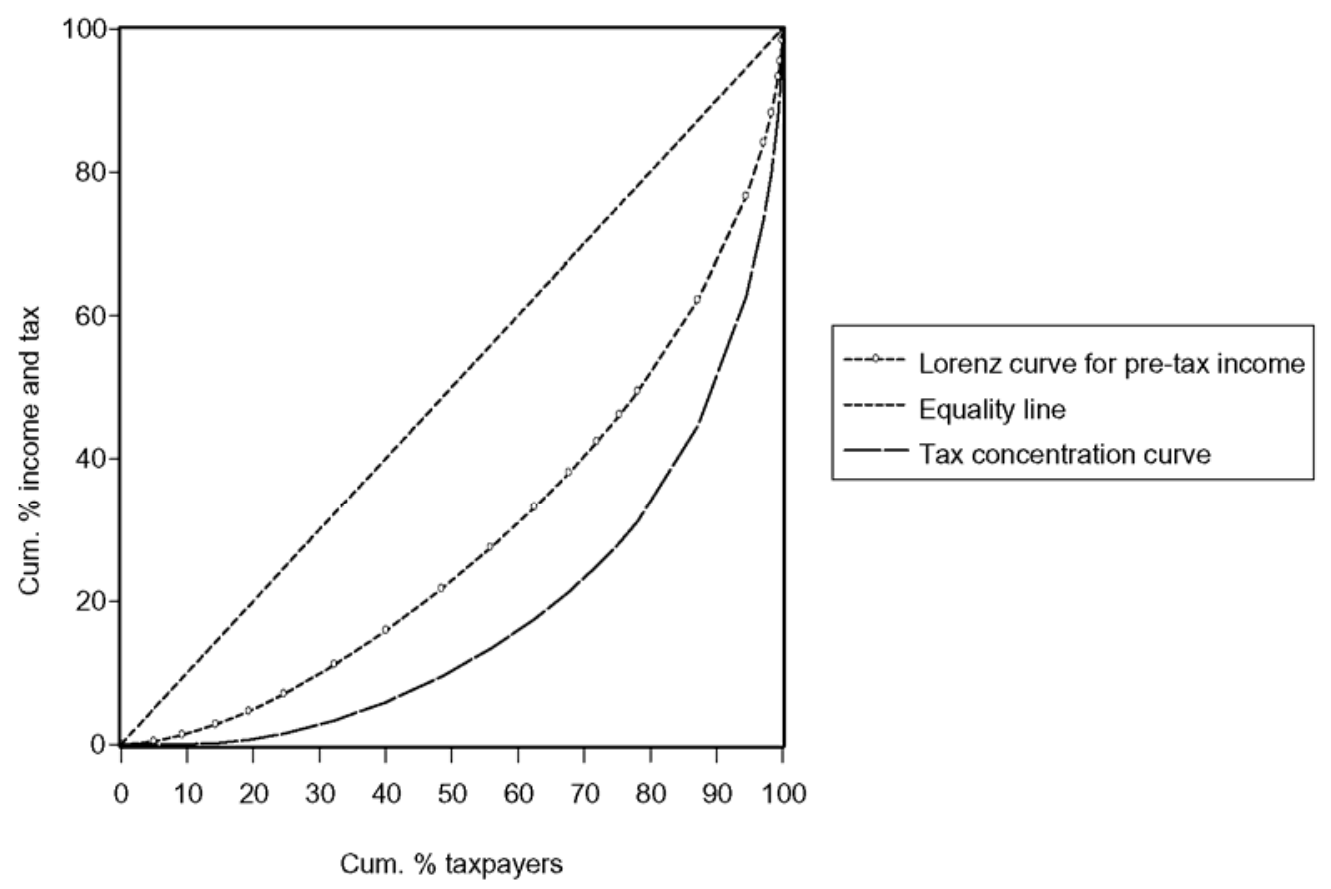

Figure 2E. Lorenz curve for taxable income and tax concentration: 2003/2004 


\section{REFERENCES}

BROWN, M. (1994). Using Gini-style indices to evaluate the spatial patterns of health practitioners: Theoretical considerations and an application based on Alberta data. Social Science and Medicine, 38(9): 1243-1256.

CAMINADA, K. and GOUDSWAARD, K. (2001). Does a flat rate individual income tax reduce tax progressivity? A

simulation for the Netherlands. Public Finance and Management, 1(4): 471-499.

COWEL, R A. (2000). Measuring Inequality (second edition, draft third edition at http://darp.lse.ac.uk/Frankweb/Frank/ pdf/measuringinequality2.pdf), Hemel Hempstead: Harvester Wheatsheaf 1995.

GLASSER, C. (1962). Variance formulas for the mean difference and coefficient of concentration. Journal of the American Statistical Association, 57: 648-654.

JEAN_YVES DUCLOS. (2000). Gini indices and the redistribution of income. International Tax and Public Finance, 7(2): 141-162.

KAKWANI, N. C. (1977). Measurement of tax progressivity: An international comparison. Economic Journal, 87: 71-80. LAMBERT, P. J. and RAMOS, X. (1997). Holizontal inequality and vertical redistribution. International Tax and Public Finance, 9: 25-37.

LORENZ, M. O. (1905). Methods for measuring the concentration of wealth. Journal of the American Statistical Association, 9: 209-219.

MUSGRAVE, R. A. and THIN, T (1948). Income tax progression 1929'-48. Journal of 'political Economy, 56: 498-514. PIGOU, A. C. (1929). A Study in Public Finance. London: Macmillan.

SCOTT, C. E. and TRIEST, R. K. (1993). The relationship between federal and state income tax progressivity. National tax journal, 46(2): 95-108.

SLITOR, R. E. (1948). The measurement of progressivity and build-in flexibility. Quarterly Journal of Economics, 62: 309-313.

TANZI, V. and ZEE, H. (2001). Tax policy for developing countries. Economic Issues, No. 27. IMF, Washington, DC. THORESEN, T O. (2004). Reduced tax progressivity in Norway in the nineties: The effect from tax changes. International Tax and Public Finance, 11: 487-506.

REYNOLDS, M. and SMOLENSKY, E. (1977). Public Expenditure, Taxes and the Distribution of Income. New York: Academic Press.

WAGSTAFF, A. and VAN DOORSLAER, E. (2001). What makes the personal income tax progressive? A comparative analysis of fifteen OECD countries. International Tax and Public Finance, 8(3): 299-315. 